\section{Fog and Mortality in the Meuse Valley.}

KOR three days last week, Dec. 3-5, a heavy fog occurred in part of the Meuse valley, in the industrial area between Huy and Seraing, south-west of Liège, as a result of which sixty-four persons and a number of cattle are dead. An official medical commission which investigated the circumstances has reported that the deaths were due to fog alone; the victims were persons who, by reason of old age or ill health, were in a low state of health.

The Ministry of Health has been in communication with the health authorities in Belgium and is informed that the recent deaths in the province of Liège are not due to any communicable disease ; the occurrence is clearly a matter of local conditions, but it may be some days before the cause is fully and authoritatively ascertained.

The fog formed part of a very extensive area of fog associated with an anticyclone that extended westwards from eastern Europe. Precise information as to the density of the fog in the afflicted area is wanting, but the accounts do not suggest that it was any greater than that of the worst London fogs, in which visibility is occasionally reduced to less than two yards. A number of upper air soundings made in Great Britain and on the Continent at this time showed that above a superficial layer of low temperature there was a rapid rise of temperature with height, the air above a height of $5000 \mathrm{ft}$. being about as warm as on an average day in August, when the annual maximum occurs at these levels. This state of affairs is, of course, very favourable for maintaining a fog, because of the extreme vertical stability that results, The atmospheric eddies that under ordinary conditions cause a constant interchange of air at different heights cannot be; present, for any cold air from near the ground if raised to a higher level would have its deficit of temperature increased by dynamical cooling, and its increasing excess of density would introduce a powerful restoring force.

Fog, however, does not originate because of such conditions ; it is generally caused by the cooling of the surface layers under a clear sky in the absence of strong wind. The evidence points to this having been the mode of origin of the fog area in Europe as a whole on this occasion. Apart from the fact that the general level of temperature was much higher than is usual in a December fog and that there was an unusually large "inversion of temperature', the meteorological conditions appear to have been characteristic of the type of weather. If any poisonous fumes or solid particles are present in the surface layers of the atmosphere, they will remain there for so long as the state of exceptional stability lasts. The presence of some such fumes as the cause of the deaths near Liège seems a more reasonable supposition than the alternative one of suffocation through sheer density of fog, because the ordinary particles of fog, whether these are drops of water or minute particles of solid matter, or, as often happens in industrial areas, a mixture of the two, occupy only a minute proportion, by volume, of the atmosphere, and can scarcely be supposed to prevent a due amount of oxygen from being inhaled even by people with impaired lungs.

If these conclusions are correct, the cause of recent deaths in the Meuse valley will be found only by more thorough investigation into the manner of the victims' death. The possibility must also be taken into account that recent industrial developments may have resulted in the liberation of poisonous products on a scale that will become destructive whenever scavenging of the air by turbulence is reduced by exceptional temperature conditions aloft.

\section{University and Educational Intelligence.}

Cambridge.-The Council of the Senate has appointed the following Committee for the James Clerk Maxwell centenary celebration: The ViceChancellor; Sir J. J. Thomson; Mr. W. Spens, Master of Corpus Christi College; Sir Joseph Larmor, Sir Ernest Rutherford, Dr. C. D. Broad, Prof. H. F. Newall, Sir Arthur Eddington, Prof. C. T. R. Wilson, Prof. F. J. M. Stratton, Dr. J. Chadwick, Dr. J. D. Cockeroft, Sir James Jeans.

The Managers of the Balfour Fund, with the approval of the Faculty Board of Biology "A ", have made a grant of $£ 30$ from the Balfour Fund to Miss P. M. Tenkin, of Newnham College, for research on "The Biology of the Smaller African Lakes".

H. G. Wager, of Emmanuel College, has been appointed to the Frank Smart University Studentship in botany.

ScholarshtPs, each of the annual value of $£ 300$, plus an allowance for apparatus and other expenses, are being offered by the Grocers Company, the object being the encouragement of original research in sanitary science. Forms of application and particulars can be had from the Clerk to the Grocers Company, Grocers Hall, E.C.2.

A SERIES of twelve Swiney Lectures entitled "The Life of the Past" will be given by Dr. T. M. Finlay in the lecture theatre of the Imperial College of Science (Royal College of Science, Old Building) at 5.30 on Mondays, Wednesdays, and Fridays, on Dec. 8-19 and on Jan. 5-16. Admission is free.

UNIVERSITY entrance tests and initial degrees form the subject of a report recently adopted by the council of the Association of University Teachers and published in the October number of the Association's Universities Review. The report surveys the existing arrangements for matriculating students in the various universities and finds them unsatisfactory, in that, on one hand, they fail to exact from every entrant valid evidence of preparedness for university work, and on the other, they exert an unhealthy influence on schools in the direction of premature specialisation. It recommends the prescription of a minimum entrance age of about eighteen years; an efficient test in the use of English; a test, to be passed shortly before entry, in four subjects, not involving such a high degree of specialisation as the higher school certificate examinations; and a certificate by the candidate's school authorities as to his powers and interests and general fitness for university work. As regards the test in English, the report expresses approval of the general principles of recommendations embodied in an article by Miss Maitland Smith which appears in the same number of the Review under the title "Entrance Examination in the Understanding and Use of English". Although the suggested improvement of the efficiency of entrance tests might be expected to rehabilitate to some extent the depreciated pass degrees of the new universities, the report urges these bodies to retrieve the mistake they made in reserving 'honours' exclusively for success in highly specialised courses, with the result that every ambitious student, whether he really wishes and is fitted to press on to the frontier of knowledge in one particular direction or not, is driven to do so. 